Univerzitet "Union - Nikola Tesla", Fakultet za menadžment Studijski program Menadžment u medijima, Sremski Karlovci

DOI 10.5937/kultura1235140B

UDK 316.775:004.738.5(497.113)"2011"

originalan naučni rad

\title{
DIGTALLAMED|JSKA KONVERGENCIJA
}

Sažetak: Proučavajući digitalne medijske tehnologije $i$ društvenoobrazovne promene pod njihovim uticajem kod nas, ispitivali smo i navike konzumenata tradicionalnih naspram digitalnih medija, kao i kredibilitet online sadržaja na koje su konzumenti upućeni. Opšti je zaključak da se internet kao digitalna platforma najčešće koristi na tradicionalan (analogan) način, kao kanal jednosmerne distribucije medijskog sadržaja, kao $i$ da se interaktivnost svodi na ostavljanje komentara $i$ uglavnom proizvoljnih stavova čitalaca. Inovativna upotreba digitalnih tehnologija koja pruža neograničene mogućnosti - od iznošenja i sakupljanja činjenica, preko povezivanja sa drugim relevantnim izvorima i dokumentima, zatim otvaranja debata i omogućavanju participacije čitalaca u definisanju društvenih problema, njihovom argumentovanom osvetljavanju iz različitih uglova, pa do pokretanja na akciju u funkciji rešavanja problema - za većinu i dalje nije interesantna. U ovom radu takođe ukazujemo na neophodnost izrade (dorade) istraživačkih metoda, tipologija i tehnika koje će biti u stanju da obuhvate što veći broj onih elemenata novih medija, koji ih razlikuju od tradicionalnih medija.

Ključne reči: mediji, digitalni mediji, medijska konvergencija, promene, korisnički generisan sadržaj

\section{Uvod $^{1}$}

Jedan od načina da istražimo novinarstvo na internetu jeste da analiziramo njegove poruke. Ovo je jedan od prvih trendova od kada su se novinarstvo i hipertekst povezali zahvaljujući digitalnoj tehnologiji.

1 Rad je nastao kao rezultat istraživanja u okviru projekta Digitalne medijske tehnologije i društveno-obrazovne promene (Projekat br. III 47020) koji se realizuje uz finansijsku podršku Ministarstva za nauku i tehnološki razvoj Republike Srbije za period 2011-2014. 
Naša hipoteza je da je konvergencija iz analognog u digitalni način produkcije novinarskih proizvoda, dovela do velikih promena u načinu pisanja i u samim proizvodima koji se nude na internetu. Zbog toga se kao nove karakteristike sve više primenjuju hipertekstualnost, multimedijalni sadržaji, interaktivnost, korišćenje različitih izvora informisanja, što je uticalo i na novinarske rutine i ritam koji se razlikuju u odnosu na praksu u tradicionalnim medijima. Takođe, konvergencija medija učinila je i da dođe do velikih promena u načinu korišćenja tradicionalnih i novih, digitalnih medija, kako u razumevanju kredibiliteta medija i medijskog sadržaja tako i u načinu uključivanja publike u kreiranje medijskog sadržaja.

Među profesionalcima i naučnicima danas postoji saglasnost oko toga da internet publikacije zavređuju novinarski status, bar isti onakav kakav imaju tradicionalni mediji kao što su štampa, radio i televizija. ${ }^{2}$ Mnogo značajnije od samog rasta broja digitalnih publikacija jeste njihova kvalitativna konsolidacija na medijskom tržištu. Kompanije koje se bave komunikacijama, i ne samo one, smatraju, gotovo bez izuzetka, da je internet strateški činilac njihove budućnosti ${ }^{3}$.

Eksponencijalni rast broja korisnika interneta rezultirao je sredinom 90-tih godina prošlog veka uspostavljanjem komercijalnih internet mreža i, paralelno sa tim, sve većeg broja dostupnih novinskih sajtova. Upravo je to vreme kada su učinjeni i prvi pokušaji da se napravi bilans stanja novinarstva na mreži, sa ciljem da se primena interneta komercijalno što bolje iskoristi. Tadašnje internet publikacije opisivane su na osnovu sledećih parametara: a) istorijski sažetak projekta, b) sistem proizvodnje vesti c) originalnost projekta i d) interaktivnost sa javnošću.

Kao referentni parametar sistema istraživanja uziman je rad Tanjev Šulc ${ }^{4}$ izložen na Indiana univerzitetu, oko kojeg je konsenzus postiglo 100 američkih online dnevnika i nedeljnika i to komercijalnog tipa. Dok je Šulcovo istraživanje bilo kon-

2 Flores Vivar J. i Miguel Arruti A., Ciberperiodismo, Ediciones 2010, Madrid 2001. Estévez J., Periodismo en la Red, Anaya Multimedia, Madrid 2002; Álvarez Marcos J. i Parra Valcárcel D., Síntesis, Ciberperiodismo, http://www.argitalpenak.ehu.es/p291content/es/contenidos/libro/se_indice_ ciencinfo/es_ciencinf/adjuntos/ciberperiodismo.pdf; Meso Ayerdi K., Introducción al ciberperiodismo, Servicio Editorial de la Universidad del País Vasco, Bilbao 2006.

3 Cornella A., Hacia la empresa en red, Gestión, Barcelona 2002; Cerezo J.M. i Zafra J. M., El impacto de internet en la prensa, Fundación Auna, Madrid 2003; Aguado J. M., E-Comunicación, Dimensiones sociales y profesionales de la comunicación en los nuevos entornos tecnológicos, Sevilla 2004.

4 Schultz T., Interactive Options in Online Journalism: A Content Analysis of 100 U.S. Newspapers, Journal of Computer-Mediated Communication 5(1), 1999. 
centrisano na aspekt interaktivnosti, inicijative iz Brazila proširile su obim istraživanja uključujući i druge karakteristike identifikovane kao specifičnosti online novinarstva: multimedijalnost, hipertekstualnost, personalizacija i pamćenje (memorija).

Internet je globalni medijski sistem, sistem masovne komunikacije, tržište za koje se vode žestoke borbe. U uslovima slobodnog protoka informacija i karaktera demokratičnosti, o internetu možemo govoriti kao o autoputu informacija, kao o uređenoj anarhiji. U takvim uslovima, od velike je važnosti razumeti istoriju medija i medijskih sistema, kako tradicionalnih, tako i onli$n e$, istoriju proizvodnje medijskog sadržaja i razumeti ponašanje korisnika tih sadržaja. Zbog toga smo se i bavili ponašanjem konzumenata online medijskog sadržaja, kako bismo dobili jasniju sliku o tome ko, šta, zašto, gde, kada i kako čini na internetu ili pomoću interneta. Ključno je razumeti ne samo ponašanje medija, tradicionalnih i digitalnih u novom okruženju i kontekstu, nego i ponašanje internet konzumenata, bilo da govorimo sa novinarskog aspekta proizvodnje sadržaja, sa ekonomskog, marketinškog, ili sa aspekta onih koji edukuju o prirodi medija i medijskih sistema.

\section{Istraživanje 1: Način korišćenja online medijskog sadržaja studentske populacije}

U nastojanju da razumemo način ponašanja i korišćenja medija među mladom, studentskom, populacijom tokom 2011. godine, sproveli smo istraživanje koje je obuhvatilo 111 studenata koji studiraju u Novom Sadu. Prvi cilj bio je da definišemo razlike prema aktivnostima korisnika u odnosu na online medijski sadržaj. Drugi je da saznamo šta korisnici znaju o prirodi interneta i online sadržaju u smislu njegovog kreiranja, distribucije i kontrole.

Rezultati istraživanja pokazali su da se najveći broj ispitanika $74,8 \%$ u toku dana najviše informiše pomoću interneta. Njih $17,1 \%$ koristi televiziju, 7,2\% štampu. Dominacija interneta je očekivana s obzirom na to da ispitanici veći deo vremena provode u urbanoj sredini gde i studiraju i gde je i prema podacima RZS-a iz 2010. godine, internet najdostupniji. Korišćenje interneta prema podacima RZS u Novom Sadu je 49,3\%.

$\mathrm{Na}$ istraživačko pitanje kako proveravaju informacije dobijene posredstvom tradicionalnih medija, najveći broj ispitanika $74,3 \%$ odgovorio je da to čini preko interneta, što samo potvrđuje pretpostavku da je internet kod mlade populacije dominantan izvor informisanja.

Na pitanje o kojim temama se najviše informišu na internetu, najveći broj ispitanika odgovara: o zabavnim, 27\% i društve- 
nim, $25,2 \%$. Slede politika sa $14,4 \%$, kultura sa $10,8 \%$ i sport sa $9 \%$. Na pitanje o svrsi korišćenja online sadržaja najveći broj ispitanika, 75\%, odgovorilo je da internet sadržaj koristi za komunikaciju i zabavu, 20,1\% odgovorilo je da internet sadržaj koristi za učenje. Zanimljivo je i to da je od 111 ispitanika samo dvoje odgovorilo da internet sadržaje koristi za donošenje važnih odluka, a samo jedan ispitanik za učešće u društvenokorisnim aktivnostima.

U pokušaju da razumemo koje informacije na internetu smatraju kredibilnim dobili smo sledeću sliku:

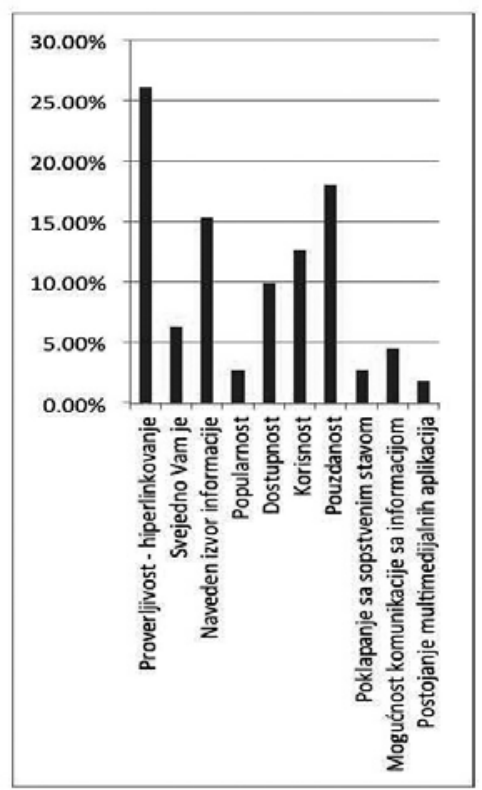

Grafikon 1.

Najveći procenat ispitanika, 44,1\%, smatra da su kredibilne online informacije one koje su pouzdane i proverljive - hiperlinkovane. Sledi 15,3\% ispitanih koji smatraju da su informacije kredibilne ako je naveden njihov izvor, a 12,6\% ispitanih smatra da su informacije kredibilne ako su korisne. Ocenjujući prema ovim rezultatima, može se naslutiti određeni stepen postojanja online medijske pismenosti i razumevanja interneta kao medija čije su najveće prednosti u odnosu na tradicionalne medije hipertekstualnost i interaktivnost. Ipak, kada pogledamo distribuciju odgovora na pitanje u vezi sa preduzimanjem konkretne aktivnosti korišćenja linkova koji se nalaze u formi određenog online sadržaja dobili smo sledeće rezultate: 


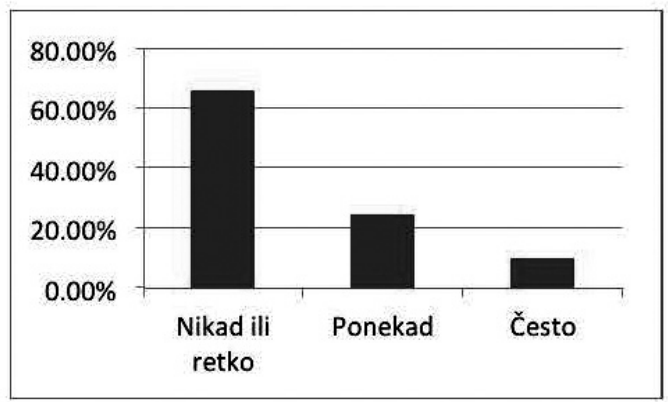

Grafikon 2.

Slične rezultate dobili smo i kada smo ispitanike zamolili da vrednuju tipove interaktivnosti medijskog online sadržaja. Najveći broj ispitanika, 39,6\%, najviše vrednuje mogućnost ostavljanja komentara kao oblika dvosmerne komunikacije, 23,4\% najviše vrednuje uvezivanje online sadržaja sa društvenim mrežama, 19,8\% najviše vrednuje mogućnost učestvovanja u kreaciji online medijskog sadržaja, dok 17,1\% smatra da je mogućnost linkovanja najvrednija. Sa druge strane, na pitanje koliko često komentarišu online medijski sadržaj i koliko često učestvuju u kreiranju online medijskog sadržaja (Wikipedia, postavljanje fotografija, teksta ili video i audio snimaka koje su sami napravili) dobili smo poražavajuće rezultate: $78,4 \%$ ispitanika nikada ili retko ostavlja komentare na medijske sadržaje, dok čak $82,9 \%$ nikada ili retko učestvuju u kreaciji online medijskog sadržaja.

Zanimljivo je i to da je polovina, 49,5\% ispitanika, odgovorila da ponekad ili često deli medijski sadržaj preko društvenih mreža.

\section{Zaključci istraživanja}

Rezultati našeg istraživanja ukazali su na činjenicu da mladi korisnici online medijskog sadržaja nemaju potpuni uvid u mogućnosti korišćenja interneta kao medija. Ako i postoje znanja o prirodi interneta kao medija, onda se ona ne primenjuju.

Možemo da zaključimo da većina ispitanika informacije na internetu smatra kredibilnim kada su proverljive (linkovane), dostupne, korisne, pouzdane i kada im je naveden izvor, da veoma cene sve karakteristike interneta kao platforme koje ga razlikuju od tradicionalnih medija, ali te prednosti retko ili nikada ne koriste. Takođe, pokazali su rezultati, internet se najviše koristi za zabavu i komunikaciju sa drugima, a najmanje za donošenje važnih odluka ili pokretanje i učestvovanje u društvenim akcijama. 
Podaci iz ovog istraživanja važni su kako za one koji upravljaju procesom konvergencije tradicionalnih medija u digitalne, tako $\mathrm{i}$ za one koji se bave medijskom edukacijom mladih.

\section{Istraživanje 2: Karakteristike štampanih medija na digitalnoj online platformi}

Tokom 2010. godine sproveli smo istraživanje kojim smo želeli da utvrdimo da li štampani mediji u Srbiji u svojim veb izdanjima koriste prednosti koje im omogućava digitalna platforma. Istraživanje je sistematski trajalo 10 dana, od 1. 09. 2010. do 10. 09. 2011. godine, praćeno je troje najčitanijih dnevnih novina $u$ Srbiji "Politika", Blic" i "Kurir" i to njihova štampana i online izdanja. U istraživanju je korišćen metod analize sadržaja, statistički metod, i komparacija, a obrađeno je ukupno 929 informativnih jedinica objavljenih u štampanim i veb izdanjima sve troje dnevnih novina.

Dobijeni rezultati istraživanja pokazali su da se analizirana štampana i online izdanja gotovo ne razlikuju, odnosno da novine u svojim internet izdanjima ne koriste $u$ dovoljnoj meri mogućnosti koje im pruža digitalna platforma.

Kada je reč o mogućnosti hiperlinkovanja i navođenja izvora informacija ili dokumenata, komparativna analiza pokazala je da između štampanih i veb izdanja analiziranih dnevnih novina

gotovo i da nema razlike.

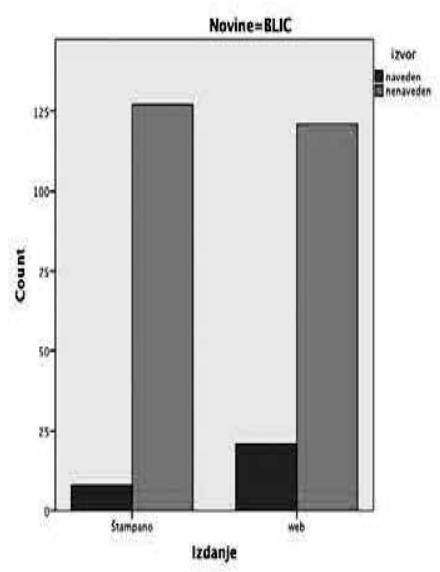

Grafikon 3.

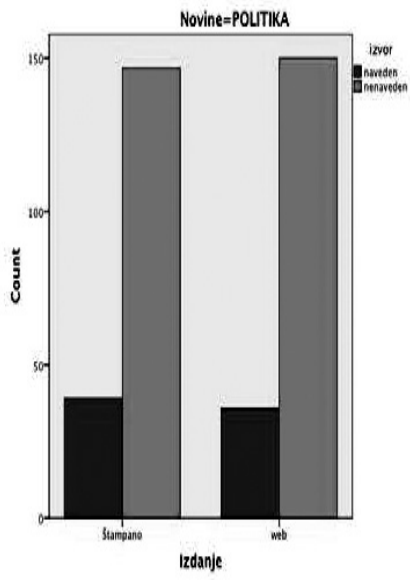

Grafikon 4. 


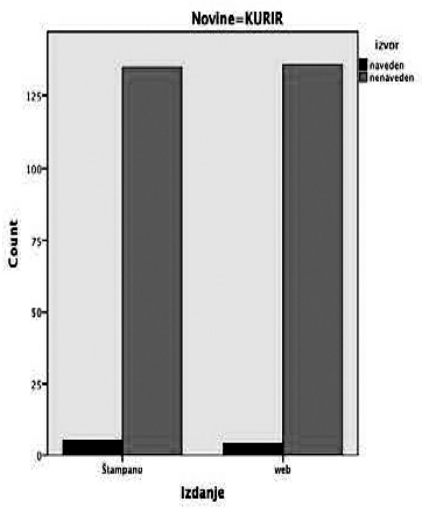

Grafikon 5.

Slični rezultati su dobijeni analizom i komparacijom navođenja autora tekstova u štampanim i veb izdanjima analiziranih dnevnih novina. Izuzetak je "Politika" koja u svom veb izdanju $\mathrm{u}$ nešto većoj meri navodi autore tekstova nego $\mathrm{u}$ štampanom.

Kada je reč o žanrovskoj zastupljenosti, rezultati istraživanja pokazali su da je zastupljenost vesti, izveštaja i intervjua u štampanim i veb izdanjima identična kod sve troje analiziranih novina. Zapaženo je i to da "Blic" u svom veb izdanju autorima dodatno pruža mogućnost da iskažu lični stav/blog.

Razlike koje su primećene u štampanim i veb izdanjima analiziranih novina najveće su kod opreme tekstova. "Politika" i "Blic" u svojim veb izdanjima mnogo više koriste mogućnosti digitalne platforme i praktično neograničenosti prostora, pa su informativne jedinice bogatije ilustrovane fotografijama, a primećena je i mnogo manja upotreba teksta, dok list "Kurir" ima identičnu opremu tekstova i u štampanom i u veb izdanju.

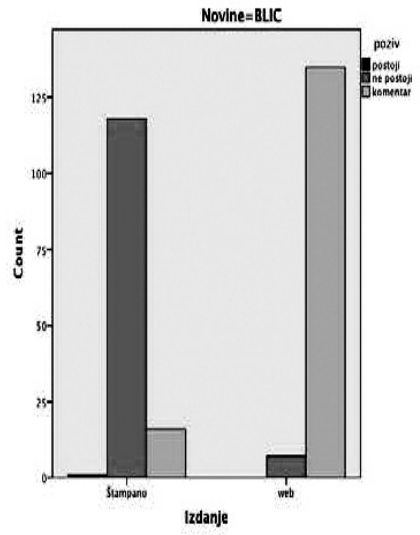

Grafikon 6.

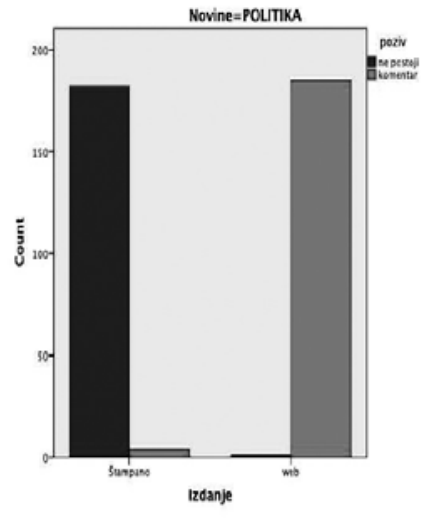

Grafikon 7. 


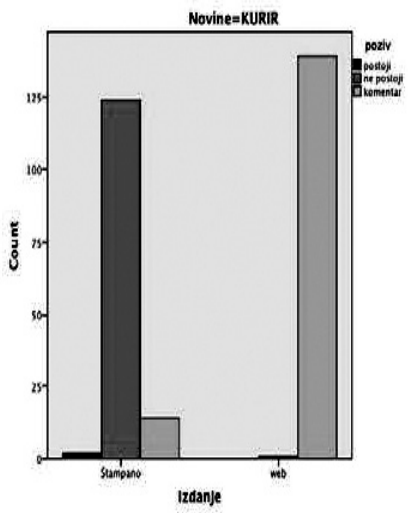

Grafikon 8.

Ipak najveća razlika između štampanih i veb izdanja analiziranih novina zabeležena je u pozivu korisnicima na komunikaciju i otvaranju mogućnosti za komentarisanje objavljenog sadržaja.

Iz rezultata dobijenih istraživanjem vidi se da dnevne novine "Kurir" i "Blic" i u štampanim i u veb izdanjima imaju otvoren prostor za komentare čitalaca i da te komentare objavljuju (što je i očekivano) više u veb izdanjima nego u štampanim. Dnevne novine "Politika" u svom štampanom izdanju ne pozivaju čitaoce na saradnju, ali ipak, i to dosta retko, objave poneki komentar čitalaca. Suprotno tome, u veb izdanju "Politika" ne objavljuje pozive za saradnju, ali u velikom broju objavljuje komentare čitalaca.

Za sve troje novina karakteristično je i to da je u veb izdanjima čitaocima pružena mogućnost pretraživanja arhiviranog sadržaja, dok to u štampanim izdanjima jednostavno nije moguće, a zapažena je i veća ažurnost i osvežavanje vesti u veb izdanjima, što takođe u štampanim nije moguće ostvariti.

$\mathrm{Na}$ osnovu ovog kratkog pregleda, ali i na osnovu ostalih dobijenih rezultata, potvrđena je glavna hipoteza istraživanja da troje analiziranih novina u svojim veb izdanjima ne koriste na odgovarajući način prednosti i mogućnosti koje pruža digitalna tehnologija i veb platforma. Stiče se utisak da se medijski sadržaj za veb izdanje ne priprema na poseban, platformi primeren način, nego se sadržaj pripremljen za štampano izdanje, uz manje dorade, "prepisuje" na online platformu.

\section{Zaključak}

$\mathrm{Na}$ osnovu istraživanja, ovde smo predočili samo deo rezultata, jasno je da digitalna medijska konvergencija, prouzrokova- 
na naglim razvojem i dostupnošću digitalnih tehnologija, ne donosi promene samo na polju medijske produkcije nego i na polju načina korišćenja medija. Tradicionalni štampani i elektronski mediji, zahvaljujući tehnologiji ubrzano gube svoju, do skoro, privilegovanu tržišnu poziciju i ustupaju mesto online medijima koji nude nove i drugačije načine komunikacije sa korisnicima. Nove digitalne medije ne karakteriše samo velika brzina nego i hipertekstualnost, interaktivnost, multimedijalnost, fleksibilnost, nepostojanje cenzure kakvu smo do skoro imali, mogućnost personalizacije online sadržaja itd. Jednosmerna komunikacija polako postaje prošlost, a štampani mediji, još uvek, ne koriste na odgovarajući način mogućnosti digitalne platforme.

Medijska konvergencija i od publike zahteva drugačiji način korišćenja medijskog sadržaja. "Zahvaljujući napretku tehnologije dobili smo nove medije. Od tog trenutka masovnom komunikatoru (novinaru, uredniku, voditelju...) prestaje ekskluzivna uloga selektora informacija; postajemo sopstveni selektori u skladu sa sopstvenim znanjem, interesovanjem i iskustvom. Novi mediji svima pružaju šansu. Svaki prijemnik je i potencijalni predajnik. Svaki član auditorijuma je i organizator i animator. Svako ima pravo na potpunu participaciju u mediju. Sistem je potpuno interaktivan i nije kontrolisan. ${ }^{\text {"5 }}$

Dakle, digitalna medijska konvergencija utiče ne samo na tehnologiju isporuke medijskog sadržaja i njegovu upotrebu, nego menja i društvenu ulogu medija, kao i ulogu svakog od korisnika. Novi mediji su otvoreniji i dostupniji, a korisnici su uključeniji. Ove promene, čini se, desile su se brže nego što su tradicionalne medijske organizacije i obrazovne institucije mogle da ih na odgovarajući način isprate. Upravo zbog toga, glavne tokove medijske konvergencije ne predvode, kao do sada, medijske organizacije. One se ne događaju iz centra prema periferiji, nego obrnuto - sa periferije prema centru. Mediji su tako prinuđeni da se promenama prilagođavaju, a korisnici da u promenama učestvuju. Novi mediji trebalo bi da razvijaju komunikaciju između novinara i korisnika. Na taj način korisnici će imati više mogućnosti, a tradicionalno novinarstvo upravo zbog toga mora da menja svoje rutine. Oni koji su na vreme shvatili novu ulogu i mogućnosti online novinarstva pružili su mnogo više svojim korisnicima uključivši ih u proces proizvodnje medijskog sadržaja. Na taj način korisnici su prestali da budu puki konzumenti, postali su aktivni kreatori informacija. Bez obzira na to što nisu profesionalni novinari, njihove informacije sma-

5 Bulatović G. i Bulatović LJ., Uvod u masovne medije, Cekom books d.o.o, Novi Sad 2006, str. 252. 
traju se korisnim i bivaju objavljene (ukoliko zadovolje stroge profesionalne kriterijume).

Ipak, konvergencija medija iz analognih u digitalne, i konvergencija publike od pasivne ka aktivnoj, čini se, dešava se u dva paralelna toka i bez ozbiljne i strateški osmišljenje saradnje. Niti mediji pokazuju preveliku želju da medijski i informativno obrazuju publiku, niti publika od medija traži smernice i uputstva kako bi generisala sadržaj koji bi bio prikladan za objavljivanje. Novinari ne koriste mogućnost dvosmerne komunikacije na online digitalnoj platformi da bi od publike dobili informacije i teme za priče, a publika novinarima, osim ličnih komentara i "smatranja", ne nudi dokumente i činjenice. Stoga smatramo da bi saradnja medija i publike na polju medijske, informativne i digitalne pismenosti, radi uključivanja i obezbeđivanja kvalitetnog koloristički generisanog sadržaja, mogla da pomogne medijskim organizacijama da obezbede bolju komunikaciju sa javnošću i komparativnu tržišnu prednost, a korisnicima i građanima da na bolji način ostvare svoja građanska i demokratska prava.

Mogućnost za uspostavljanje boljeg odnosa između medija i društva kroz sistematski rad na uspostavljanju medijske i informativne pismenosti (MIP) uočio je i Evropski Parlament. Decembra 2008. godine Evropski Parlament usvojio je rezoluciju u koju su unete preporuke iz izveštaja o "medijskoj pismenosti u digitalnom svetu". Ova rezolucija prepoznala je značaj medijske pismenosti i preporučila obavezno i zakonom regulisano uključivanje medijskih modula u obuke nastavnika na svim obrazovnim nivoima. Evropski Parlament takođe je prepoznao UNESCO-vu ulogu u promovisanju medijskog obrazovanja kroz, između ostalog, Grünwaldske Deklaracije $(1982)^{7}$ i Pariske Agende: 12 preporuka za medijsko obrazovanje $(2007)^{8}$. Njihov razvoj opisan je kao "indikativ pozitivnih trendova koji pažnju usmeravaju ka političkim i regulatornim okvirima koji vode i podržavaju sistematsko bavljenje medijskim obrazovanjem".

Zahtevi gledalaca, slušalaca i čitalaca da učestvuju, debatuju i komentarišu posredstvom medija sve više postaju trajno obeležje društva. Ukoliko mediji ne nauče da na efektan način upotrebljavaju korisnički generisan medijski sadržaj, publika će se prebaciti na druge medijske platforme koje aktivno ohrabruju

\footnotetext{
6 http://eur-lex.europa.eu/LexUriServ/LexUriServ.do?uri=OJ:C:2010:045E:0 009:0014:EN:PDF

7 http://portal.unesco.org/ci/en/files/27310/12150121753MEDIA_E.pdf/ MEDIA_E.pdf

8 http://www.ifap.ru/pr/2007/070625ba.pdf
} 
participaciju auditorijuma. Stoga bi bilo potrebno sačiniti smernice koje bi medijima pomogle da se na bolji način suoče sa potrebama kako publike tako i medijske industrije. Te smernice bi trebalo da budu od koristi ne samo onima koji u medijima rade, nego i regulatorima, medijskim obrazovnim organizacijama, široj medijskoj industriji, javnosti i svima ostalima zainteresovanim za promovisanje medijske, informativne i digitalne pismenosti.

\section{LITERATURA:}

Aguado J. M., E-Comunicación, Dimensiones sociales y profesionales de la comunicación en los nuevos entornos tecnológicos, Sevilla 2004.

Álvarez Marcos J. i Parra Valcárcel D., Síntesis, Ciberperiodismo, http://www.argitalpenak.ehu.es/p291content/es/contenidos/libro/se_indice_ciencinfo/es_ciencinf/adjuntos/ciberperiodismo.pdf

Bulatović G., Bulatović LJ. i Arsenijević O., Proposal of research typologies for analysis of journalists products in syber-media, Proceedings of Scientific-researsh interdisciplinary project Digital media technologies and social-educational changes that is financed by the Ministry of Education and Science of the Republic of Serbia, in: Knowledge, Education, Media, eds. Andevski M., Arsenijević O., Bulatović G. i Bulatović Lj., Fakultet za menadžment, Novi Sad 2011, str. 48-59.

Bulatović G. i Bulatović LJ., Uvod u masovne medije, Cekom books d.o.o, Novi Sad 2006.

Cerezo J. M. i Zafra J. M., El impacto de internet en la prensa, Fundación Auna, Madrid 2003.

Cornella A., Hacia la empresa en red, Gestión, Barcelona 2002.

Estévez J., Periodismo en la Red, Anaya Multimedia, Madrid 2002.

Flores Vivar J. i Miguel Arruti A., Ciberperiodismo, Ediciones 2010, Madrid 2001.

Khan A. W., Foreword to Mapping Media Education Policies in the World, United Nations, New York 2009.

Meso Ayerdi K., Introducción al ciberperiodismo, Servicio Editorial de la Universidad del País Vasco, Bilbao 2006.

Novak S., Bulatović G. i Bulatović LJ., Razumevanje kredibiliteta i način korišćenja online medijskog sadržaja kod studentske populacije, u: Na putu ka dobu znanja, Fakultet za menadžment, Sremski Karlovci 2011.

Prtets C., Media literacy in a digital world, Motion for a European Parliament resolution, 2008.

Schultz T., Interactive Options in Online Journalism: A Content Analysis of 100 U.S. Newspapers, Journal of Computer-Mediated Communication 5(1), 1999. 


\title{
LJ. LJ. BULATOVIĆ, G. BULATOVIĆ i O. ARSENIJEVIĆ
}

http://eur-lex.europa.eu/LexUriServ/LexUriServ.do?uri=OJ:C:2010:04 5E:0009:0014:EN:PDF

http://portal.unesco.org/ci/en/files/27310/12150121753MEDIA_E.pdf/ MEDIA_E.pdf

http://www.ifap.ru/pr/2007/070625ba.pdf

http://www.argitalpenak.ehu.es/p291content/es/contenidos/libro/ se_indice_ciencinfo/es_ciencinf/adjuntos/ciberperiodismo.pdf

Ljiljana Lj. Bulatović, Goran Bulatović and Olja Arsenijević University "Union-Nikola Tesla", Faculty for Management -

Program of Studies for Management in the Media, Sremski Karlovci

\section{DIGITAL MEDIA CONVERGENCE}

\begin{abstract}
By studying digital media technology and social changes in education under their influence in Serbia, we have examined the consumers' habits, traditional versus digital media, as well as the credibility of online content that consumers are referred to. The general conclusion is that the Internet as a digital platform is commonly used in traditional (analogue) mode, as a one-way channel for distribution of media content and interactivity that is tantamount to leaving comments and generally arbitrary attitudes by readers. The innovative use of digital charting technology that provides unlimited possibilities - from collecting and presenting facts, through linkage with other relevant sources and documents, opening debates and facilitating participation of readers in defining social problems, their argument-based illumination from different angles to launching campaigns in the function of solving the problem - still fails to appeal to most. In this paper, we also point to the necessity of developing (redeveloping) research methods, typologies and techniques that will be able to encompass a larger number of those elements of the new media which differ from the traditional ones.
\end{abstract}

Key words: media, digital media, media convergence, changes, user generated content 